\title{
The Bronze Age Mortuary Vessels of Ban Non Wat
}

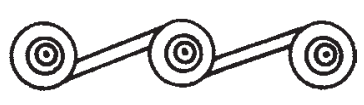

TIM BARRIBEAU

\section{INTRODUCTION}

This article analyzes the Bronze Age mortuary ceramics from the site of Ban Non Wat, Thailand, in order better to understand how these vessels relate to chronology and the changes that occur in burials through the time. This investigation employs statistics to analyze the occurrences of particular ceramic forms, including seriation, near neighbor, and correspondence analyses. Furthermore, spatial analyses of both the layout of mortuary vessels and of burials were undertaken, as were numerical comparisons of these features to indicate if certain pot forms are tied to wealth.

Ban Non Wat in Changwat Nakhon Ratchasima, Thailand, is a prehistoric site that was occupied from the Neolithic to the historic period. Beginning in 2002, it has been excavated as part of the "Origins of Angkor" research program, which has been investigating archaeological sites in the region for more than a decade. Ban Non Wat stands out in terms of the breadth of artifacts uncovered and the area of the site excavated. This article concentrates on the Bronze Age, a still highly contentious period due to the current debate surrounding chronology and social organization (Muhly 1988; O'Reilly 2000, 2003). The large scale of the excavation at Ban Non Wat has allowed us firmer insight with regard to Bronze Age chronology and social complexity.

Ban Non Wat is a "moated" prehistoric site, meaning it is ringed by a series of ditches and banks, creating a number of moats around the location. The moats were most likely used as a method of water control, but have been dated to the Iron Age (McGrath and Boyd 2001), and so are not dealt with in this article.

The site of Ban Non Wat is unique among Southeast Asian excavations in the amount of data recovered. Excavated for over 20 months, Ban Non Wat has provided a breadth of information, which offers the opportunity to gain further insight into the prehistory of the Mun River valley. This excavation has unearthed one of the largest mortuary samples in Southeast Asia, with over 600 burials recorded. For this study, only Bronze Age burials that included ceramics, and were clearly photographed, could be analyzed. This created a sample of 87 burials, over 4000 artifacts, and more than 750 vessels.

Bronze Age burials were interred in rows, with individuals often being buried with ceramics of a distinctive tradition. The combination of a large sample of complete

Tim Barribeau received his Master of Arts from Department of Anthropology, University of Otago, Dunedin, New Zealand. He currently works as a freelance science and technology journalist in the USA. 
burials associated with a distinctive artifact set, and changes in burial tradition throughout the Bronze Age, provides data that is amenable to analysis. This temporal change is of significant archaeological interest and is archaeologically distinct, as it is bookended by changes to both the burial and artifactual record. This article presents the analyses of the ceramic vessels associated with the burials, the burials themselves, and other associated artifacts in order to identify changes in the nature of interments as they relate to social organization. The data presented were gathered during the first four of the seven seasons of excavation, using a wide variety of numerical, statistical, spatial, and comparative analyses. The analyses will identify the manner in which individuals were buried and how this relates to other burials within the site, as well as how this information can be used as a relative chronological indicator, as an absolute chronology has only just been undertaken (Higham and Higham 2009).

\section{CERAMIC VESSELS}

In this study, the ceramic vessel typology is based on that used by O'Reilly $(1999: 157)$ for his analysis of the site of Ban Lum Khao, because this allowed for inter-site comparisons. This system is based on discrete vessel characteristics, as proposed by Shepard (1971). O'Reilly's typology allowed for 15 different forms of pots, with numerous sub-forms for minor variations (O'Reilly 1999:163-166). Due to the differences between the sites, there were unavoidably a number of forms at Ban Lum Khao that did not occur at Ban Non Wat and vice versa. To this end the typology was extended to 19 forms (Fig. 1).

Shepard's (1971) methodology for creating a typology is based on vessel profiles. Decoration and use are not accounted for, but rather the silhouette is used to classify according to a lexicon of basic forms. In this typology, five factors are looked at in order to characterize the form of the vessel. These are: upper vessel shape, contour, body shape, neck shape, and presence or absence of a pedestal (Barribeau 2007:11$15,18-24)$.

These identifying features allowed for a wide range of pots to be readily identified to form. However, the typology does not take into account decoration as a factor in the process. Regardless, decorations were recorded for the pots, with six different forms noted: cord marked, red slipped, burnished, lugged, impressed, and painted. Of these, cord marking, red slipping, and burnishing were all very common, with impressed patterns being slightly more common. Painted and lugged pots were rare during the Bronze Age of this site.

Factors other than vessel shape and decoration were also considered. The aim of this study was to investigate ceramics within the larger context of the burials, therefore their placement and associated artifacts were also important.

\section{FUNCTION}

Many of the forms appear to be non-functional given that fewer than 20 percent of the vessels have pedestals, with the rest having either slightly flattened bases or no modification at all. This raises questions about the practicality of the pots for day-today use. In a situation where the majority of vessels have no means of stabilizing the body, and where some that do have bases also have lips so large as to cause the pots to easily topple (forms 5e, 5f, 8a, and 11a), one must consider the possibility that these 


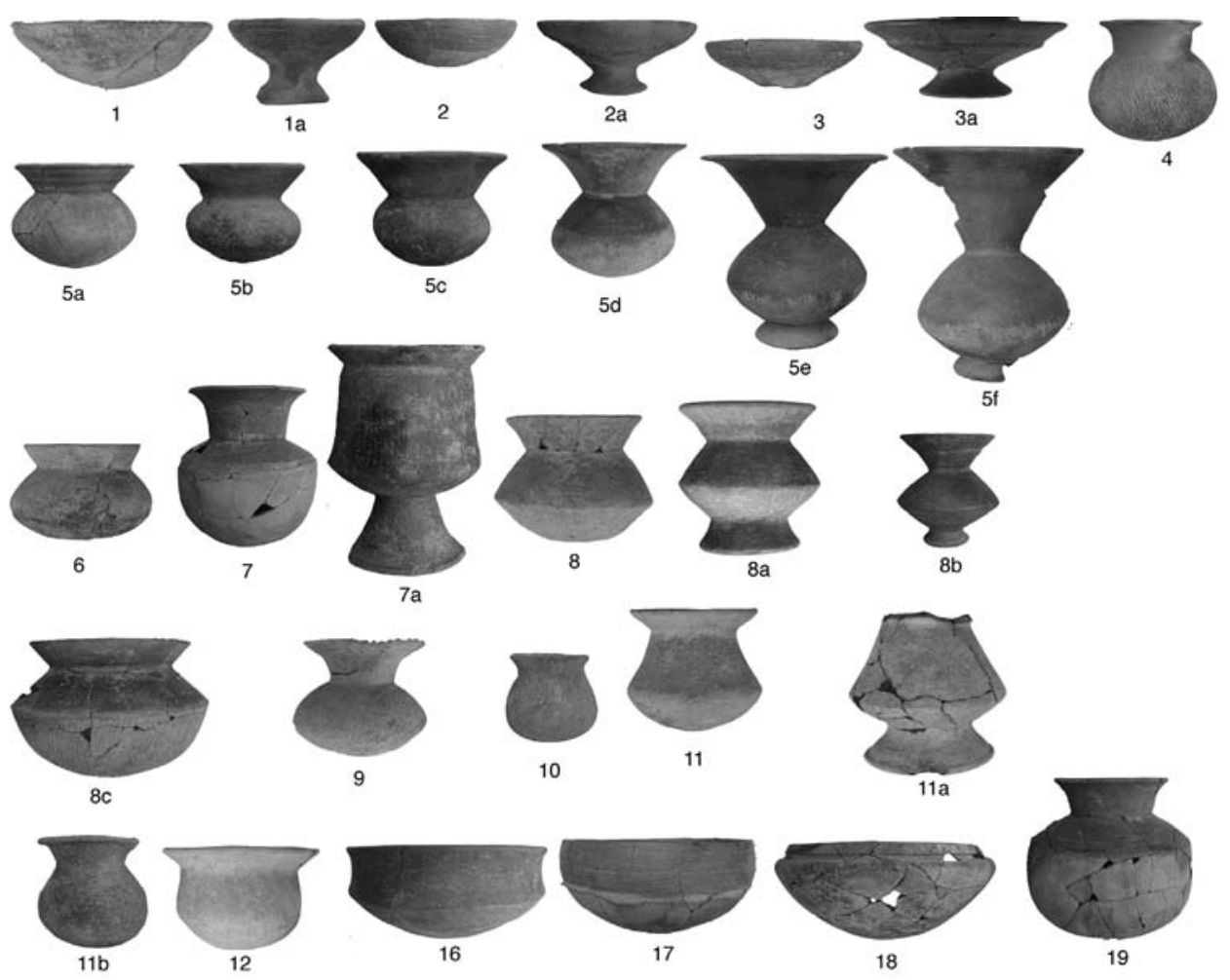

Fig 1. Pot forms from Ban Non Wat (not to scale).

vessels may have been more ceremonial than practical. However, this fails to take into account whether any other tools may have been used to support the pot during use. For instance, form 6 pots would not be able to stand easily on their own, yet they could easily be suspended over a fire for cooking, via cord suspension around the neck or being supported by green bamboo twigs over the fire.

MacDonald (1980, as cited in O'Reilly 2004) also discusses vessel accessibility with regard to size of a vessel's mouth. He states that cooking vessels will have low stability and high accessibility; while storage vessels will have a higher stability and would be less accessible, serving vessels would have both high accessibility and high stability. According to this argument and the calculations undertaken by O'Reilly (1999:167), forms such as 6, 9, and 13 would be suitable for cooking as they have high accessibility and low stability. Forms 1, 1a, 2, 2a, 3, and 3a would all have been suitable for serving, while forms $8,8 \mathrm{a}, 11$, and 11 a would have the suitable attributes for storage. However, some vessels seem to defy explanation using this method of analysis. Forms $4,5 \mathrm{a}, 5 \mathrm{~b}, 5 \mathrm{c}, 5 \mathrm{~d}$, and $5 \mathrm{f}$ all have low stability and low accessibility.

\section{WEALTH}

One of the fundamental issues currently debated in Southeast Asian archaeology concerns social differentiation during the Bronze Age. It has been suggested that the 
Bronze Age of Southeast Asia, specifically in Thailand, was significantly different in comparison to the rest of the world in that there appears to be little in the way of social differentiation with the introduction of bronze working (Muhly 1988; O'Reilly 2003; White 1995). The crux of the debate revolves around the way in which bodies were interred, and whether or not social differentiation can be inferred from these burials.

The debate over social differentiation in Thailand is difficult to approach, as there are no ethnographic data to support the arguments. In order to understand whether social differentiation is evident during the Bronze Age of Ban Non Wat, the analyses must look at goods associated with individual burials. Interments are one of the few areas where we can confidently associate artifacts with individuals. At Ban Non Wat, the majority of the data obtained is from mortuary contexts, due to the large number of interments found. There is also a lack of strongly contextualized data from nonburial features within the site. When performing analyses of this nature, questions must be raised about how to treat the material culture being analyzed. Are all artifacts to be treated equally in terms of the analysis, or should special attention be given to those artifacts that are identified as being more important than others? How does one identify importance, or social significance? Is there a difference between the importance of a shell as compared to a pot, or between two different forms of pots? How does this reflect on the status of the individual?

Tainter (1978:125) discussed the use of "energy expenditure" as a marker of social status, reasoning that a person of high rank will have a larger amount of energy investment in their burial. The problem with this method of measurement is that it is extremely difficult to measure the energy expended, and difficult to know exactly what is being measured (Shimada et al. 2004).

Related is the concept of "production steps" in the assignation of wealth value to a ceramic artifact. The basis of this model is that prestige goods take more steps to create during the production phase, giving the vessels greater worth (Feinman et al. 1981). This method allows for highly decorated vessels of a complex shape to be weighted differently than simple utilitarian wares. However, it does not account for the length of time accorded to each step or the importing of goods (such as clay or the finished product) (O'Reilly 1999:232). Certain vessels may have more time spent on one area of the production than others. Such a phenomenon is ignored under this system, even though these extended steps may be significant. Likewise, it does not take into account imported materials or goods that may be prestige items solely on the basis that they came from an exotic source.

O'Reilly uses direct artifact counting as a measure of wealth. While acknowledging that such a method loses "some resolution" $(1999,2004: 308)$ this method avoids suppositions as to the value of certain artifacts over others. It ignores contextual information completely. It does not provide any weight in one direction or the other as to the value of the object, nor does it attempt to guess the social and symbolic implications of various artifacts. Each artifact is worth exactly as much as any other, doing away with any potential bias that arises. O'Reilly's (2004) model provides data that are straightforward to compare and analyze. For these reason this is the method used in this study. 


\section{METHODS}

\section{Seriation Analyses}

Seriation analyses of the burials were undertaken using WinBASP, an application designed for the statistical analysis of archaeological data. These analyses took into account the ceramic vessels in the burials. Including other variables in the analysis was impractical due to the fact that the variables involved in analyzing position, vessel clusters, and associated artifacts would complicate the investigation. The seriation diagram (Fig. 2) serves to create a relative chronology of the site, as well as provide a method of comparison and integration of results from other analyses. This collaboration of information can help to provide insight into the temporal and spatial layout of the interments, and help us to understand the location of the burials and associated grave goods.

\section{Correspondence Analyses}

Correspondence analysis was undertaken using the application WinBASP. Correspondence analysis is a descriptive technique designed to analyze and simplify multivariate data into an easily interpretable graph. This has produced a graph showing obvious clusters of burials, based on similarity of the vessels (Figs. 3-5). Twelve clusters were identified, including one super-cluster, made up of two lesser clusters.

\section{Other Analyses}

Spatial analyses were used to observe the manner in which chronologically linked burials were interred. Numerical analyses were used to understand how pot form, vessel location, and associated mortuary goods related to one another with regards to artifact counts.

\section{RESULTS}

\section{Seriation Analyses}

In conjunction with the standard seriation graph, a correspondence analysis seriation graph was generated using the same data set and the results from the correspondence analysis (Fig. 2). Correspondence analysis is a multivariate analysis that interprets complex multivariate data into easily interpreted two-dimensional graphs. It can also be used for seriation analysis by using one of the axes and the artifact counts to produce a seriation graph. Correspondence analysis has been shown to provide accurate chronologies based on known dates in Southeast Asia (Lertrit 2003), making it appropriate to use in this situation. This provides a different method of sorting the data, and it can serve to confirm or refute the results originally found.

The seriation analysis showed three distinct divisions across the Bronze Age burials that were analyzed. Firstly, the burials with a large number of artifacts, the "superburials," are all early in the chronology, followed by the majority of burials, then a cluster of later burials, marked by pot types 7 and 8 (Fig. 6). The layout of these burial divisions can be seen in Figure 7. 


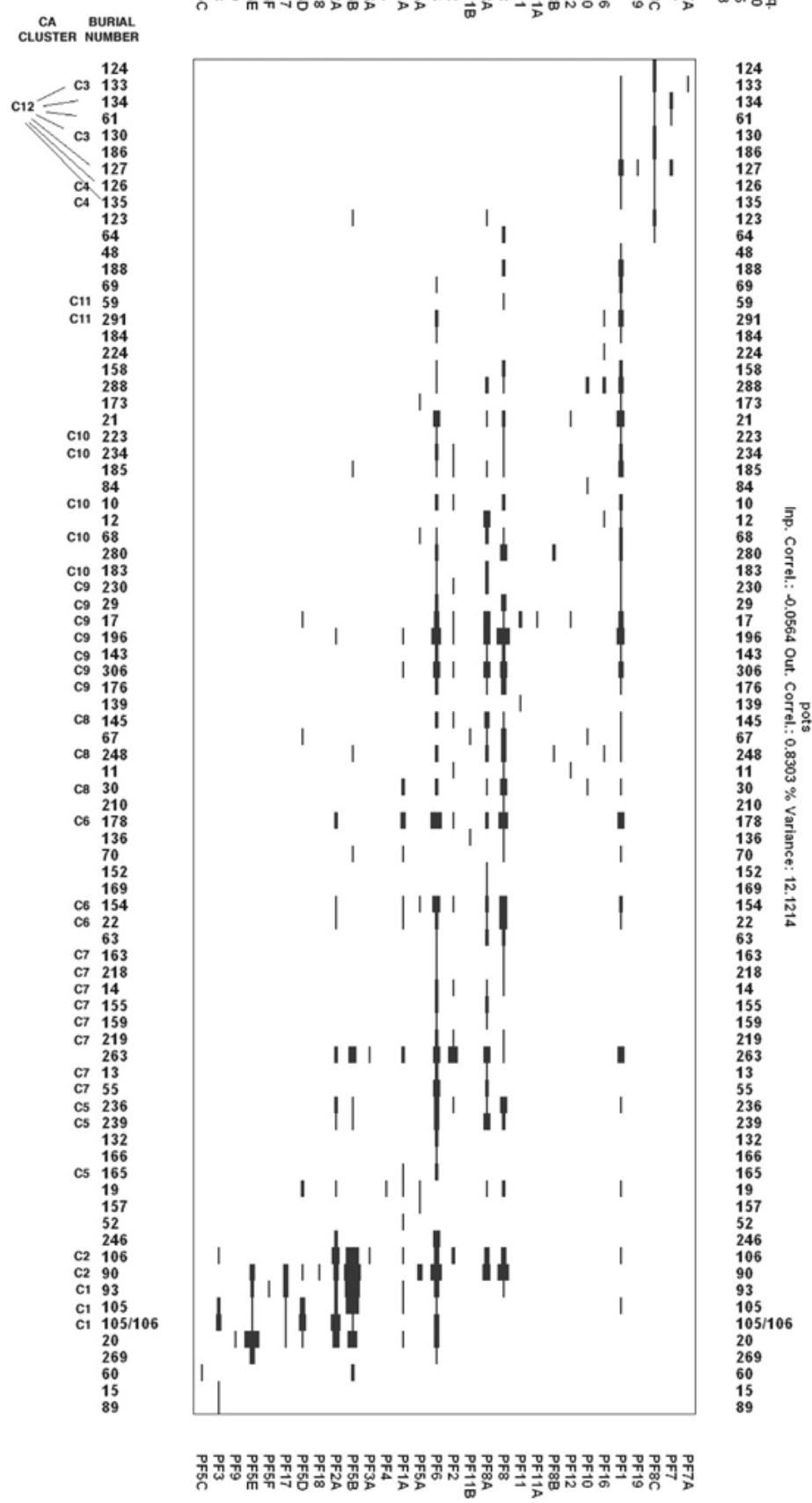

Fig. 2. Seriation graph including all burials with ceramics, with correspondence analysis clusters marked. 


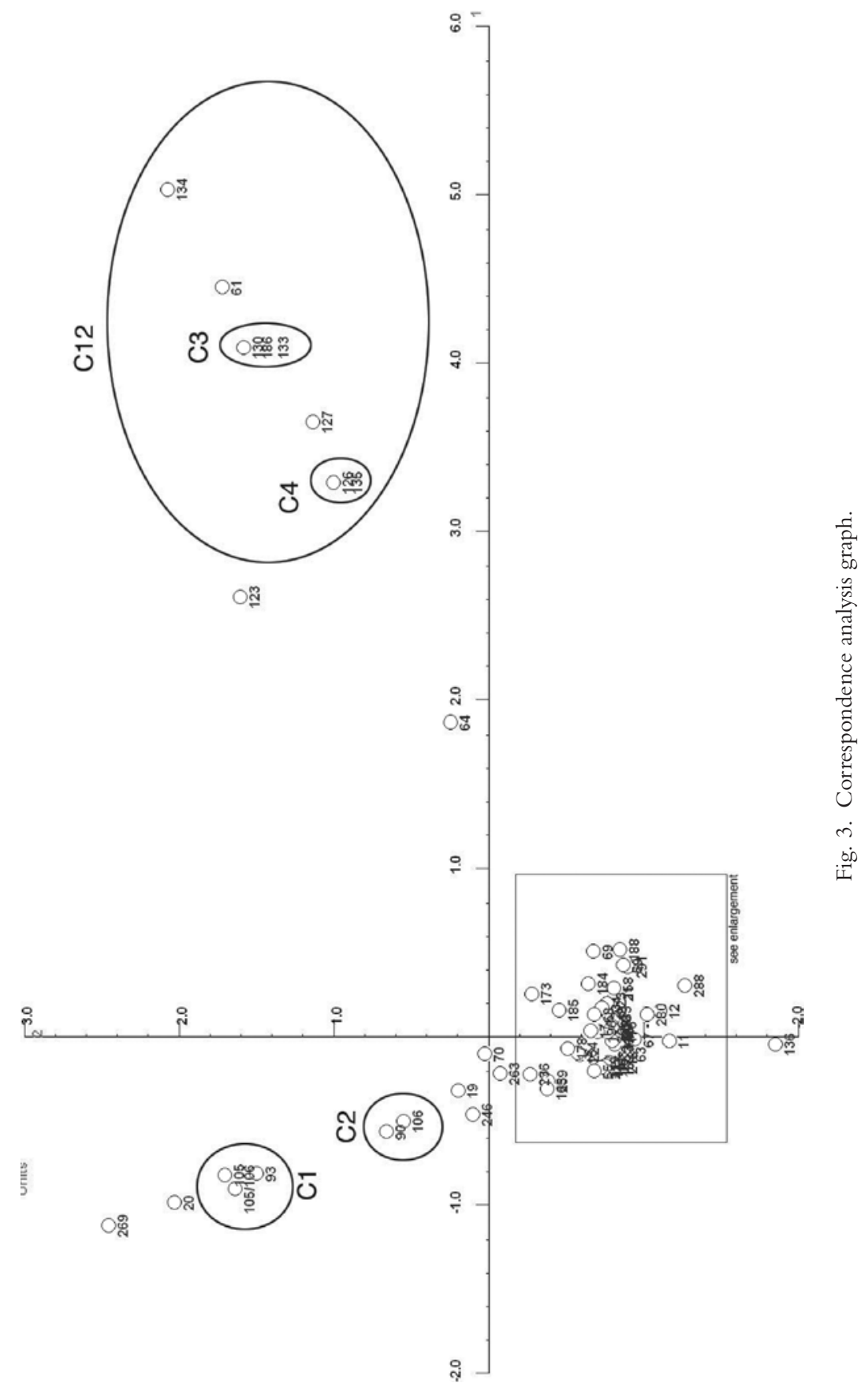




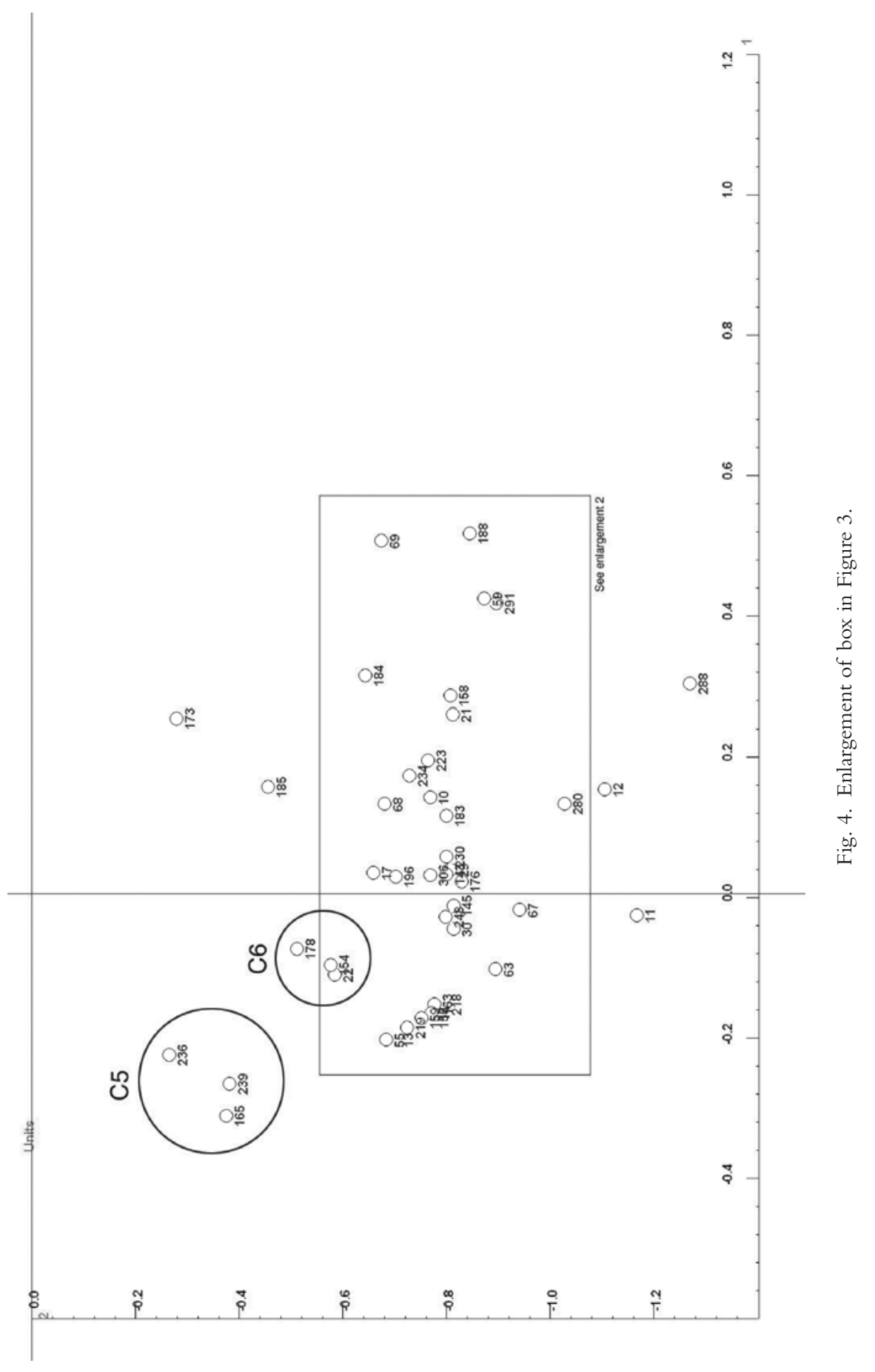




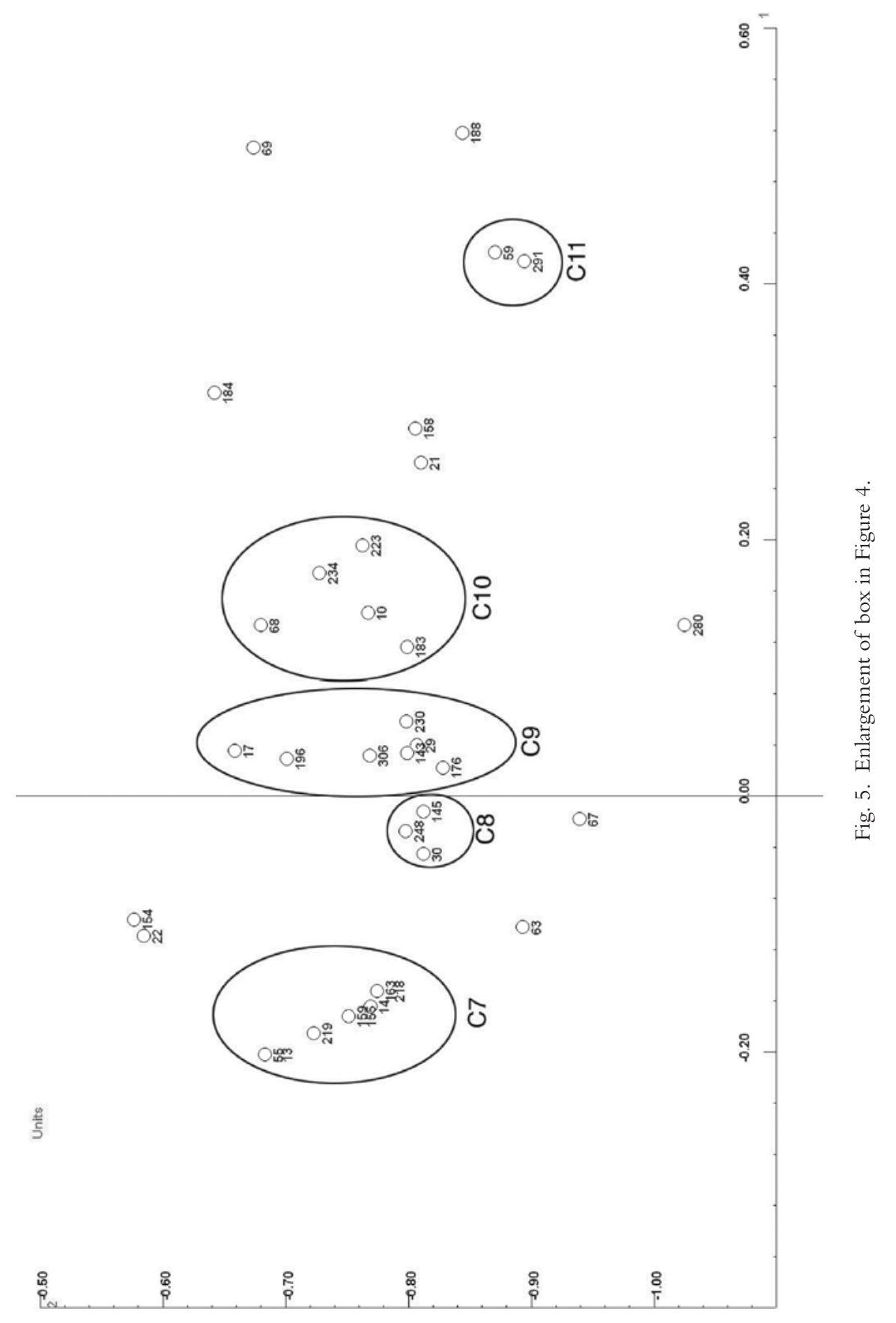




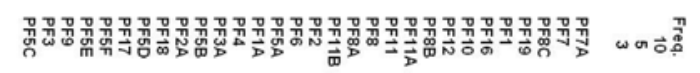

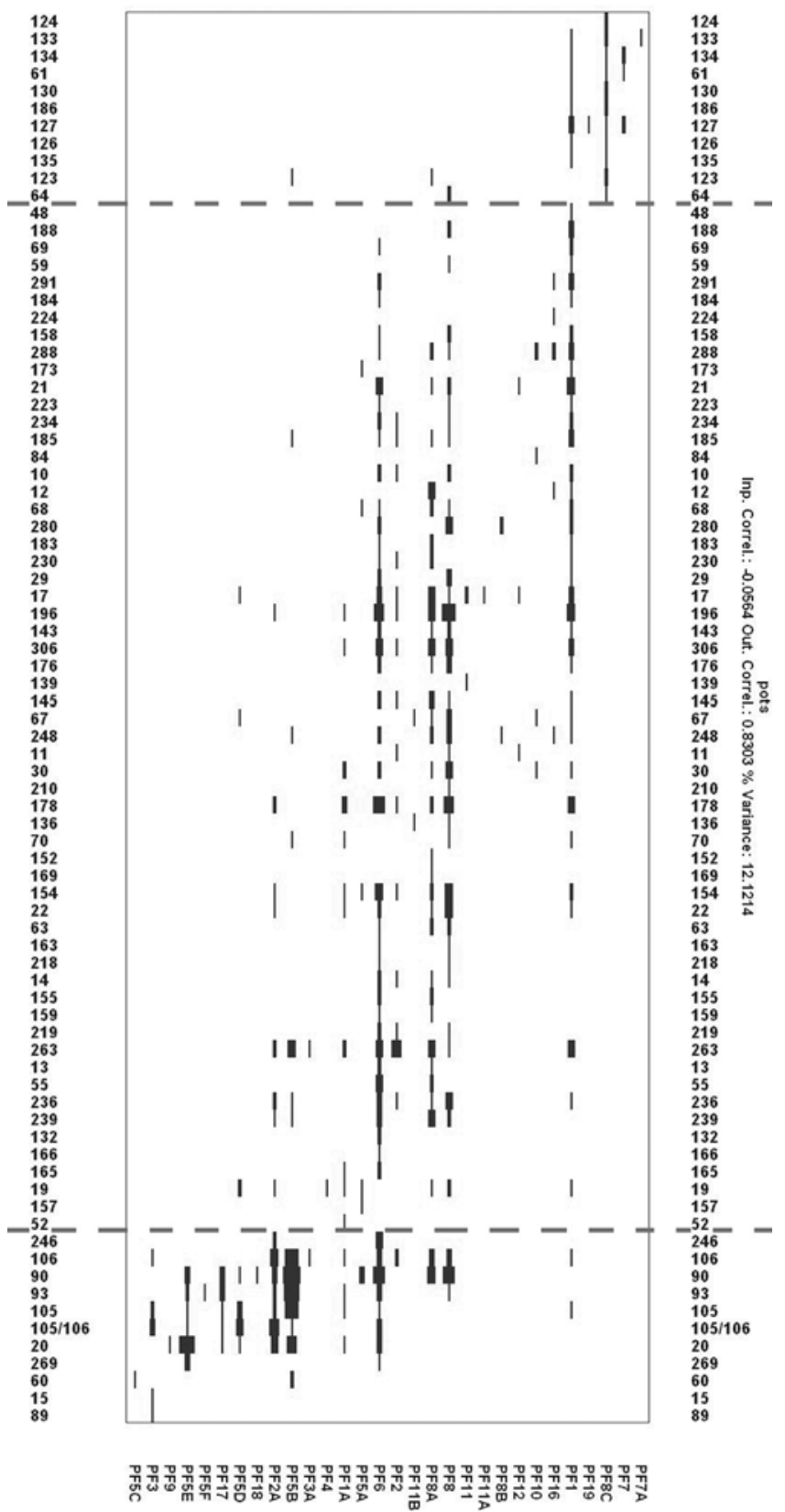

Fig. 6. Chronology of burials divided into early (lowest), middle, and late (highest). 


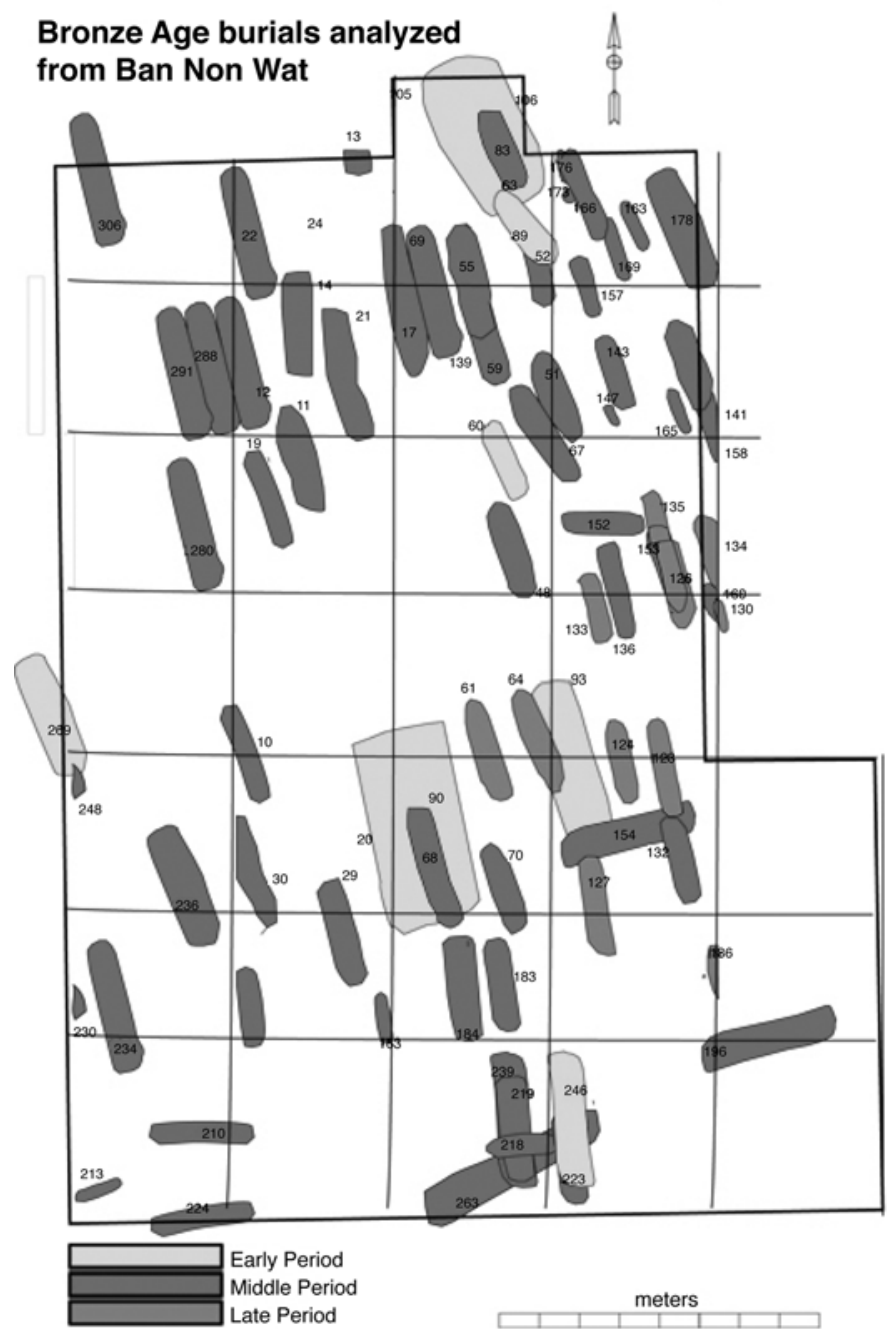

Fig. 7. Layout of burials according to period.

With the results gathered from the seriation analysis, certain things are evident. First, most of the rich "super-burials" are clustered toward one end of the graph. The "super-burials" (such as burials 20, 90, 105, and 106) were extremely large burials cut into the basal layer of the site, containing dozens of pots, shell and marble bangles, bronze artifacts, and hundreds of shell beads. This clustering is due to the nature of the goods found within the graves, namely the presence of bronze tools and form 5 pots, both of which are found prominently in the early Bronze Age. They also tend to be cut much deeper than later burials, often cutting through the Neolithic and into the natural substrate. The seriation combined with the stratified nature of the burials places them early in the chronology.

Common ceramic forms such as 1,6 , and 8 are found throughout the record. Form 1 seems to occur more often in the later burials, 8 in the middle period, and 6 
slightly more toward the early interments. There are also forms that have fairly strong links to one end of the chronology or the other. Forms 7 and $8 \mathrm{c}$ seem particularly clustered around the later burials, while forms 2,3 , and the many varied forms of 5 all seem to be found in the earlier interments. These earlier burials also have a wider variety of pots in the interments, as well as a greater number (Fig. 2). This may indicate a shift in the nature of the burial goods, moving away from diversity and large numbers and into a more standardized and simplified burial culture. The less common forms tend to appear across the entire length of the chronology, such as forms 16 and 10 . Both are relatively rare, and only occur in a small number of burials, yet are across a wide temporal breadth.

Some forms and their sub-forms appear at chronologically quite different times in the site. While form 1 appears across the entire site but more often in the later burials, form $1 \mathrm{a}$ is primarily an early occurrence. This is likewise true of forms 2 and $2 \mathrm{a}$. As discussed earlier, these vessels may have doubled as lids. It is apparent that pedestaled/ lid variations are early forms, whereas the dish form occurs throughout the time period under consideration. Evidently, the pedestaled variation fell out of use after the early Bronze Age.

With most of the other sub-forms, there seems to be significant crossover between the basic form and the variant. All of the heavily varied form 5 vessels are found at the early stages of the Bronze Age. Forms 8 and $8 \mathrm{a}$ are present across the entire time period, but $8 \mathrm{~b}$ and $8 \mathrm{c}$ are more common toward the late Bronze Age. The variation of pot form 11 occurs toward the middle of the chronology, form 3 vessels appear very early, and the forms of 7 are situated very late in the chronology.

This suggests that the sub-forms occur within the chronological confines of the more basic forms. It implies that the typology that has been developed for Bronze Age ceramics is robust and relevant. The forms proposed under the typology correspond to the relationships that are apparent in the seriation. The forms and sub-forms occur together, usually with significant overlap. If the typology were inappropriate and incorrect, one would imagine that there would be only a random overlap between the form and sub-forms. If they were not linked in some manner, there would be no reason why there would be any sort of correlation between them. Rather, we would expect them to be distributed temporally across the site with no apparent link. What is evident is that forms and sub-forms are connected and the sub-forms appear to be variations on the predominate super-form. Therefore the typology used is one that reflects the manner in which the pots were crafted and is a valid form of analysis.

There is one area that may have caused the chronology to be problematic. It is conceivable that the "super-burials" that are very early in the chronology, may in fact be socially rather than chronologically separate. The distinctive nature of the burial goods of these interments may be different enough from the contents of the other burials that the seriation defines the "super-burials" as being chronologically distinct, whereas they may be socially distinct instead. Whether or not this is a factor will be discovered when radiocarbon dates are made available for the relevant interments. Until that time, it must be assumed that the theoretical underpinning to the chronology is sound, and that the results are valid.

\section{Correspondence Analyses}

Correspondence analysis produces a two-dimensional graph based on similarly occurring grave goods, where burials close to each other in the graph are interred with 
similar sets of artifacts. The analysis showed a number of clusters of burials, all of which are discussed in detail below (Figs. 3-5). When these clusters are mapped against the seriation graph, certain objects that occur prominently in the clusters can be used as chronological markers.

When the results of this analysis are compared to the seriation table produced previously, definite patterns emerge. Almost all the clusters occur very close together on the relative chronology provided by the seriation (Fig. 2). The large outlying cluster C12 (which is composed of clusters C4 and C3) is at the upper limit of the chronology; C11 is quite late; C10, C9, C8, C6, C7, and C5 are toward the early stages; and $\mathrm{C} 1$ and $\mathrm{C} 2$ are at the beginning. There is no overlap of clusters whatsoever in the seriation. All of the clusters identified in the correspondence analysis graph come across distinctly in the seriation, without any mingling. This means the clusters identified were distinct chronologically and had a unique lexicon of burial goods. The seriation, correspondence analysis, and near neighbor analysis all support one another, with the clusters identified closely linking to the seriation, which in turn shows that it is statistically possible to link burials together based on mortuary ceramics, and use that link to relatively date them. This then relates to what is seen in the ground and what can be inferred about the society that buried people at Ban Non Wat.

When compared against the chronology, the three chronologically differentiated sets of burials can be noticed as distinct groups in the correspondence analysis. The early burials have a negative $\mathrm{y}$-axis value and a positive $\mathrm{x}$-axis value, the middle period burials have a negative $\mathrm{x}$-axis value, and the later burials have positive $\mathrm{y}$-axis and positive $\mathrm{x}$-axis values. Interestingly, all of the burials that occur in the earlier half of the chronology are on the negative side of the $\mathrm{x}$-axis. These distinct and observable clusters show that burial artifacts other than pots reinforce the differences noted within the chronology.

\section{Other Analyses}

A spatial analysis of these trends revealed changes in the way in which the burials were laid out across the site. The earliest burials were scattered across the site, with the occasional north-south cluster, changing over time to east-west clusters; later burials were arranged in small, tight groupings. A spatial analysis of all the burials, not just of these clusters, shows a similar trend, starting with apparently randomly arranged burials, proceeding to north-south burial rows, then to east-west burial rows, and finally to small, indistinct clusters.

Numerical analyses were undertaken to explore how the variables associated with the mortuary vessels coincided with other artifacts and the location of those vessels within the burial. Artifact counts were compared to the form and location of the vessels. The percentage of artifacts within the burial that were vessels was considered, as was the coinciding of vessel form and the presence of bronze artifacts. From this analysis, forms $3 \mathrm{a}, 5 \mathrm{a}, 5 \mathrm{~b}, 17$, and 18 appeared in burials with a significantly greater than average number of artifacts. According to the relative chronology, these forms all occurred early in the sequence.

Burials with forms 2, 2a, 5a, and 7a have a high percentage of artifacts that are vessels; burials with forms 4, 8c, and 16 have a low percentage of artifacts that are vessels, and a small number of artifacts; finally, burials with forms $5 b, 5 c, 11 c, 12,17$, and 19 also have a low percentage of vessels but an average number of artifacts. The average number of artifacts per burial was 16 . 
There also appears to be an inverse correlation between the number of non-ceramic artifacts and the percentage of artifacts that are vessels, whereby the increase in non-ceramic artifacts is not matched by an equal increase in numbers of vessels. When there is a wide variety and large number of other artifacts, there is a corresponding drop in occurrences of the vessels.

The presence of bronze artifacts was taken into account, and bronze was found more often in burials with a higher number of artifacts (average of $n=24$ ) and a higher percentage of vessels $(n=9$, against a site average of $n=6)$. Forms $3 \mathrm{a}, 5 \mathrm{f}, 7 \mathrm{a}$, and 18 were only ever found in burials with bronze artifacts. What is also interesting is that all of these forms are early in the chronology except form 7a. Forms 1a, 2, 2a, $5 b, 7,8 c$, and 17 are often found associated with bronzes, but not exclusively. These forms are primarily from early to the middle of the chronology, with a few being toward the end. Forms 8b, 10, 11, 12, and 16 are never found with bronze. These all occur later in the seriation chronology, but interestingly are not associated with low artifact count burials. This trend indicates a change from early burials with a large number of artifacts and rare vessel forms associated with bronze, to bronze being an object found in graves of average artifact wealth in the middle period, to not being present in these middle-range burials toward the end. This trend could be seen as symptomatic of a decrease in importance or availability of bronze in burial situations.

\section{DISCUSSION OF RESULTS}

Trends can be observed in the burial record from the analyses described above. Rather than distinct, isolated burial traditions, the manner of interment seems to have gradually evolved over the course of the Bronze Age, from the extremely wealthy superburials to burials with increasingly fewer burial goods and more closely packed interments. These changes occur as a gradual evolution, a slow alteration in burial practices through time. Early in the chronology we find burials that are interred with large numbers of objects and particular forms of pots: $3 \mathrm{a}$, the various sub-forms of 5 , forms 17 and 18. The number of artifacts gradually decreases, bronze artifacts are found less commonly, and other forms of vessels rise in prominence (forms 7, 8 and sub-forms, and 16). The burials change from being distributed widely around the site, to north-south groupings, then to east-west-aligned clusters, before finally changing to small, discrete burial clusters.

While there is a certain amount of homogeneity in the evolution of the burials, there are certainly differences between the burials of the same time period. For instance, burials 19 and 165 are closely linked in the chronology but have different burial inclusions (Fig. 2). This means that, on some level, there must have been distinctions between the interred even during the same time period. Based on the evidence discussed in this article, we cannot hazard to guess why and how this difference occurs, but there is certainly something distinguishing these burials from each other.

One issue that remains is the lack of evidence for contemporaneous "poor" burials that occupy the same time period as the early super-burials. It is an inherent difficulty in a chronology provided by a seriation graph, where these early super-burials are different enough in their burial inclusions that the analysis cannot successfully mark other graves as belonging to this same time period. Unfortunately, without greater evidence and absolute dates, we cannot place coexisting burials with different artifacts at this time period. While evidence does present itself for the middle period 
burials, which may suggest a similar pattern in the earlier ones, such a statement can only be confirmed with additional data.

The evidence suggests that at the beginning of the Bronze Age, Ban Non Wat was going through a period of social change and differentiation. The changes in burial style, and the existence of concurrent burials with both large and small amounts of mortuary goods, shows that there was social divergence across the Bronze Age, even if we cannot be sure of the form this divergence took.

\section{ACKNOWLEDGMENTS}

First and foremost I wish to thank Professor Charles Higham for not only giving me the chance to work on this site, but also providing me with the ample data for the analyses I have undertaken, and for supervising the writing of both this article and the thesis on which it was based. I would also like to thank Dr. Ratchanie Thosarat for her assistance in the field, providing photographs of the vessels, and providing me the opportunity to work in Thailand, and Brian Niven for assisting with the considerable number of statistical analyses required for this article.

\section{REFERENCES CITED}

BARRIBEAU, T.

2007 The Bronze Age Funerary Ceramics of Ban Non Wat. M.A. diss. University of Otago, Dunedin.

Feinman, G. M., S. Upham, and K. G. Lightfoot

1981 The production step measure: An ordinal index of labor input in ceramic manufacture. American Antiquity 46(4): 871-884.

Higham, C., And T. Higham

2009 A new chronological framework for prehistoric Southeast Asia, based on a Bayesian model from Ban Non Wat. Antiquity 83(319): 125-144.

LERTRIT, SAWANG

2003 On chronology-building for Central Thailand through an attribute-based ceramic seriation. Asian Perspectives 42(1): 41-71.

McGrath, R. J., and W. E. Boyd

2001 The chronology of the Iron Age "moats" of northeast Thailand. Antiquity 75(288):349-360.

Muhly, J. D.

1988 The beginnings of metallurgy in the Old World, in The Beginnings of the Use of Metals and Alloys: 2-20, ed. R. Maddin. Cambridge, MA: The MIT Press.

O’Reilly, D. J.

1999 A Diachronic Analysis of Social Organization in the Mun River Valley. Ph.D. diss. University of Otago, Dunedin.

2000 From the Bronze Age to the Iron Age in Thailand: Applying the heterarchical approach. Asian Perspectives 39(1-2): 1-19.

2003 Further evidence of heterarchy in Bronze Age Thailand. Current Anthropology 44(2):300-306.

2004 Ceramic Categorization and Description, in The Excavation of Ban Lum Khao: 231-300, ed. C. Higham and R. Thosorat. Bangkok: The Thai Fine Arts Department.

SHEPARD, A. O.

1971 Ceramics for the Archaeologist. Washington, DC: Carnegie Institution of Washington.

Shimada, I., K.-I. Shinoda, J. Farnum, R. Corruccini, and H. Watanabe

2004 An integrated analysis of pre-hispanic mortuary practices: A Middle Sican case study. Current Anthropology 45(3):369-402.

TAINTER, J. A.

1978 Mortuary practices and the study of prehistoric social systems, in Advances in Archaeological Method and Theory: 125, ed. M. B. Schiffer. New York: Academic Press. 
White, J. C.

1995 Incorporating heterarchy into theory on socio-political development: The case from Southeast Asia, in Heterarchy and the Analysis of Complex Societies: Comments: 101-123, ed. R. Ehrenreich, C. Crumley, and J. Levy. Washington, DC: American Anthropological Association.

\section{ABSTRACT}

This article analyzes the evidence for the beginnings of social differentiation in the Bronze Age site of Ban Non Wat in Northeast Thailand through the analysis of Bronze Age burials and the artifacts associated with those interments, with special emphasis paid to ceramic vessels. Vessel form, decoration, location, and associated artifacts were the primary bases for the analyses. Statistical, numerical, and spatial analyses were performed to gain a fuller understanding of the social basis for burial practices and to examine the implications of interment practices for inferring social structures at Ban Non Wat. A seriation chronology was developed based on vessel forms and their relative frequencies in various burial contexts in order to determine the temporal implications of various patterns of interments. The results showed that there were distinct changes in the mortuary practices across the Bronze Age, with early burials being spread around the site and having a large number and wide variety of artifacts, which then slowly developed into a tradition of burials with fewer artifacts in more localized areas. Over this time period, the occurrences of bronze artifacts decreased, and there was a change in the forms of associated pottery found. There also appear to have been specific forms of pots that are associated with burials that had large numbers of interred artifacts, or are found with bronze goods. Keywords: Thailand, Bronze Age, vessels, pottery, seriation, burials. 